\title{
THE
}

\section{Older adults learning technology in an intergenerational program: Qualitative analysis of areas of technology requested for assistance}

\author{
Dara L. LoBuono \\ University of Rhode Island \\ Skye N. Leedahl \\ University of Rhode Island, skyeleedahl@uri.edu \\ Elycia Maiocco \\ University of Rhode Island
}

Follow this and additional works at: https://digitalcommons.uri.edu/hdf_facpubs

Creative Commons License

c) (†) $\ominus$

This work is licensed under a Creative Commons Attribution-Noncommercial-No Derivative Works 3.0 License.

\section{Citation/Publisher Attribution}

D.L. LoBuono, S.N. Leedahl, E. Maiocco (2019). Older adults learning technology in an intergenerational program: Qualitative analysis of areas of technology requested for assistance. Gerontechnology, 18(2), 97-107 https://doi.org/10.4017/gt.2019.18.2.004.00 Available at: https://doi.org/10.4017/gt.2019.18.2.004.00

This Article is brought to you for free and open access by the Human Development and Family Science at DigitalCommons@URI. It has been accepted for inclusion in Human Development and Family Science Faculty Publications by an authorized administrator of DigitalCommons@URI. For more information, please contact digitalcommons-group@uri.edu. 


\title{
Older adults learning technology in an intergenerational program: Qualitative analysis of areas of technology requested for assistance
}

\author{
Dara L. LoBuono MS RD LDN ${ }^{a}$ \\ Skye N. Leedahl $\mathrm{PhD}^{\mathrm{b}, *}$ \\ Elycia Maiocco $\mathrm{BSc}^{\mathrm{C}}$
}

\begin{abstract}
${ }^{a}$ Department of Nutrition \& Food Sciences, University of Rhode Island, Kingston, RI, USA; ${ }^{b}$ Departments of Human Development, Family Studies, and Political Science, University of Rhode Island, Kingston, RI, USA; 'Health Studies Program, University of Rhode Island, Kingston, RI, USA; *Corresponding author: skyeleedahl@uri.edu
\end{abstract}

\begin{abstract}
D.L. LoBuono, S.N. Leedahl, E. Maiocco. Older adults learning technology in an intergenerational program: Qualitative analysis of areas of technology requested for assistance. Gerontechnology 2019;18(2):97-107; https://doi.org/10.4017/gt.2019.18.2.004.00 Adults 65 and older are adapting to technology at a slower rate compared to the overall population. Research has shown that programs can assist older adults in learning and embracing technology. However, little information exists about what specific forms of technology older adults are interested in learning and for what purposes. To describe areas of technology older adults are interested in learning and why this study examined qualitative data from an intergenerational service-learning program in which students in higher education assist and mentor older adults with and about technology that older adults want to learn. Data was analyzed from in-depth observation logs maintained by students after each educational session. Eight themes emerged related to areas of technology older adults were interested in learning about: basic functions, staying connected, organization, leisure, managing photos, productivity, managing money, and health. Of the 827 total phrases coded, the top themes related to technology use were: basic function $(28 \%)$, staying connected $(23 \%)$, and organization $(15 \%)$. The majority of older adults requested help with their devices' basic functions, including an orientation to mobile devices, tablet and/or computer, making tactile functions easier, creating accounts, setting and restoring passwords, and understanding basic cyber security. Findings from this study reinforce that older adults are interested in learning the technology basics, which may lead to utilization of technology for social, civic, and productive engagement purposes in addition to managing health. This study provides valuable information for organizations that help older adults learn technology and for entities that design technology or want to increase technology adoption for older adults.
\end{abstract}

Keywords: older adult learning, technology program, technology adoption, digital divide, intergenerational service-learning

\section{INTRODUCTION}

Older adults (65+ years of age) are the fastest growing population in the United States, and technology adoption among this population is occurring at a slower rate compared to the overall population (Pew Research Center, 2017). This gap between those who do and do not have access to technology is known as the digital divide (van Dijk, 2006). Technology use has become a fundamental aspect of society, including work, education, communication, leisure, and managing health (Czaja et al, 2006). Lack of digital adoption can create disparity and disenfranchisement among older adults, especially since

technology has been viewed as a vehicle to help facilitate aging in place (Reeder et al., 2013). While access to technology among older adults has been examined, few studies have examined technological uses and purposes for using technology among older adults (Tsai, Shillair, Cotten, Winstead, \& Yost, 2015). Using data from University of Rhode of Island (URI)'s Engaging Generations: Cyber-Seniors Program, the purpose of this study was to describe the specific areas of technology older adults are interested in using and for what purpose. 
Understanding areas of technology older adults are interested in will help reinforce technology use and help further increase digital competence among older adults (van Deursen \& Helsper, 2015). Continued technology use will help older adults achieve personal offline benefits. Technology can facilitate aging in place through helping older adults maintain their independence (Heart \& Kalderon, 2013). This is attributed to the fact that technology-using older adults tend to have better access to health information, enhanced ability to perform daily tasks (Czaja et al., 2006), and stronger social connectedness and inclusion (Blažun, Saranto, \& Rissanen, 2012). Additionally, technology can improve quality of life (QOL) (Czaja et al., 2006), increase self-efficacy (Eastin \& LaRose, 2000; Karavidas, Lim, \& Katsikas, 2005), and prevent cognitive decline (Tun \& Lachman, 2010).

Few programs and interventions designed to increase technology use among older adults have investigated the types of technology older adults are interested in using. Instead many past interventions focus on a particular device or program, such as an iPad or Facebook (Peek et al., 2016). Consequently, limited information exists regarding the types of technology older adults are interested in using and why, though a couple of studies do shed light on technology use and interests. For example, Hilt and Lipschultz (2004) conducted a series of interviews in a pilot group of internetusing older adults and found all participants used email, and those who did surf the web were seeking personal information rather than news. These older adults were using the internet for a wide range of activities, including online communities, games, digital photography, and accessing health information. Delello and McWhorter (2017) also conducted an iPad training program for 19 older adults from a senior living center via a university service-learning initiative. They found that many older adults wanted to use their iPad to take and share pictures, search for information on the internet, read books, videoconference, use social media, watch movies, read the news, play games, and send and receive emails. By the end of the training, the majority of participants were using Facebook, checking email daily, searching for interests, and taking photos. This study builds on these findings by looking at a large sample of older adults who were allowed to pick which devices and programs they are most interested in using.

Understanding technology use and preferences among older adults can help increase the rate of technology adoption and utilization (Peek et al., 2016). Heinz et al. (2013) assessed older adults' perceptions of technology and found older adults were enthusiastic to learn forms of technology that preserve independence and
QOL (Heinz et al., 2013). A Pew research study found that $48 \%$ of internet-using older adults need someone to set up or show them how to use a new device, and $34 \%$ of internet-using older adults lack confidence in their ability to use electronic devices to perform online tasks. Despite older adults' enthusiasm to use technology, many older adults need training in using their devices and programs of interest.

Intergenerational programs, such as the URI's Engaging Generations: Cyber-Seniors Program can serve as an avenue to teach older adults about technology and positively influence attitudes toward technology, digital use, and competence (Leedahl et al., 2019). The URI's Engaging Generations: Cyber-Seniors Program uses reverse mentoring and a service-learning approach, where university students help older adults learn about technology for experiential education, while developing communication and teaching skills. Service-learning is an organized community service activity, where students partake in experiences for credit to promote hands-on education (Underwood \& Dorfman, 2008). A reverse mentoring, service-learning program can create a mutualistic, open relationship where mentors and mentees share knowledge and experiences (Speitzer, 2006). This program is novel because most interventions helping older adults learn how to use technology do so in group settings, but research indicates older adults want to learn about technology through personalized one-onone sessions (Betts, Hill, \& Gardner, 2017). This study describes technology use and preferences of older adults learning to use technology in both one-on-one or small group settings.

The URI's Engaging Generations: Cyber-Seniors Program utilizes concepts from Knowles's theory of andragogy (Knowles, 1984). The theory of andragogy is a constructivist approach to learning where adults draw on their own experiences and knowledge to create new learning. Knowles characterizes adults' readiness to learn as linked to the relevance of the subject and ability to emerge as autonomous, self-directed, and internally motivated learners. As a result, an instructor can create an effective adult learning environment by basing objectives on the adult's needs, interests, and skill level with activities that are relevant, handson, and applicable to the adult's goals. To help keep learning relevant, the theory encourages instructors to explain reasons for teaching specific skills, focus on tasks adults can perform, involve the learner in solving real-life problems, and continually assess the adult's progress and adjust as needed (TEAL Center Staff, 2011). The theory has been used previously in older adult populations learning to use technology (Fink \& Beck, 2015), and this study works to inform this theory. 


\section{Research aim}

The primary aim of this qualitative study is to describe specific areas of technology older adults that are interested in using and why. Most programs training older adults to use technology have yet to allow older adults to choose the medium of technology they are interested in using and for what purpose. Allowing older adults to pick devices they are most comfortable with and topics that interest them can help older adults see the personal relevance of technology in their everyday lives, thus helping older adults to see offline benefits from technology adoption.

\section{Methods}

This study utilized data gathered from student observation logs from the URI Engaging Generations: Cyber-Seniors Program. For more details on the URI Engaging Generations: Cyber-Seniors Program, please see Leedahl et al. (2019). In summary, this program incorporates an interdisciplinary approach to teach older adults about technology and includes faculty and students from the Colleges of Health Sciences, Pharmacy, and Arts \& Sciences. Older adults and students can participate in the program through one of four program models: one-on-one sessions, small group sessions, drop-in sessions, and a matching program where the older adults are matched with a student based on technological or social interests. The research for this project has been approved by the University Institutional Review Board.

\section{Student-maintained observation logs}

Data from 109 pages of student-maintained indepth observation logs collected from the 20162017 academic year were analyzed. Sessions from all four program models were analyzed from six senior centers throughout the state, the Osher Center for Lifelong Learning (OLLI), and a PACE organization. After each session, students documented the name of the older adult and pertinent demographic data, the amount of time spent with the older adult, topics covered during the session, strategies used to teach older adults, and how they connected with older adult participants beyond technology. Most observation log entries were a quarter of a page. Students documented spending anywhere from 15 minutes to 1 hour with older adults. Approximately 199 older adults and 27 student mentors participated in the program according to the 313 observation log entries that were included in this analysis. This analysis focuses on one-on-one and group sessions. The majority of observation entries describe individual sessions, meaning one student and one older participant. Eighteen observation log entries described sessions where two students worked with one older adult, and nine entries described group sessions, which ranged from one to three mentors and two to seven older adults. This count is quite accurate, but due to some inconsistencies with how students recorded their sessions, this number is an approximation.

\section{Qualitative analysis}

A narrative approach was used to analyze qualitative data and identify emerging themes; this approach analyzes qualitative data to understand meanings participants give to themselves, their surroundings, and their lived experiences through storytelling (Josselson, 2011). The primary researcher went through the observation logs and came up with initial codes based on the specific aim of this project and discussed these codes with the faculty researcher. During this time, the primary researcher and faculty researcher collapsed overlapping themes and added additional codes related to technology use among older adults (Figure 1). An agreement was reached on initial codes. After this, the primary researcher and a research assistant went through and coded the first four pages of observation logs separately and convened to compare coding. A percent agreement of greater than $80 \%$ was achieved, and disagreements were discussed and reconciled. The observation logs were then uploaded into Nvivo 11 . The primary researcher and the research assistant separately performed line-by-line coding of the entire document in Nvivo using ten identified themes. This involved reviewing each line of text and assigning one or more codes to each piece of data describing older adults' technology use. An inter-coder reliability was calculated and found acceptable, with agreement of $81.86 \%$ and kappa coefficient (k) of .5989 (Bazeley \& Jackson, 2013; Saladaña, 2016). The primary researcher and the research assistant then met to discuss differences in coding and a consensus was met. Finally, the primary researcher and faculty researcher met to collapse and finalize themes. After all data was coded and codes collapsed into final themes, we identified the frequency of each theme across the observation logs by calculating percent of each phrase code compared to the total number of codes. In total, there were 827 phrases/sentences coded across 313 sessions. Many sessions had multiple codes because many topics were covered during the session. Additionally, some of the phrases were double coded. For instance, if someone received assistance with organizing their emails into folders, this was coded as getting organized and communication.

\section{Results \\ Technology use}

The eight major themes related to technology use identified are summarized in Figure 1 and reported as percentages of each phrase coded related to the major themes. 


\section{Older adults learning technology}

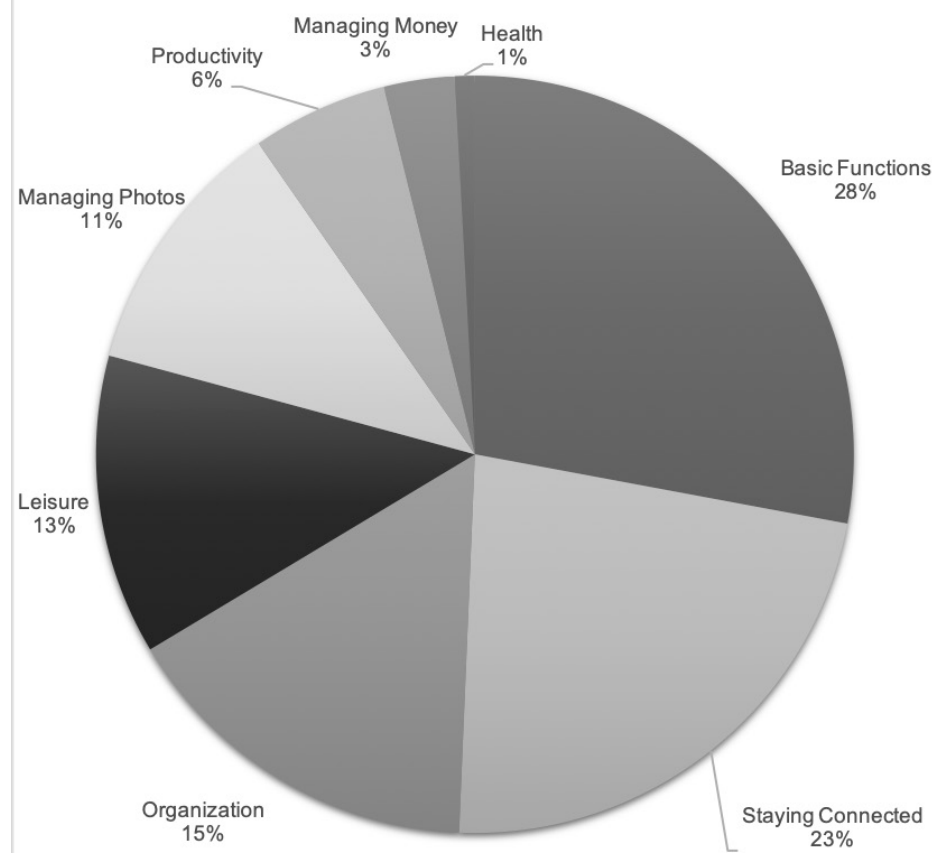

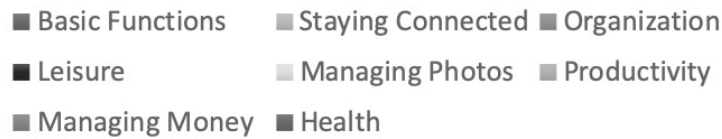

Figure 1. Technology use among older adults him feel stupid."

To acquaint older adults with technology, some mentors would go through the functions of each program or app on the device, and older adults would decide if the program would be useful.

Older adults also wanted to learn about different settings, features, and the device interface. Topics covered during sessions included: airplane mode, changing displays, find my iPhone, ringtones, brightness, and volume. Two older adults inquired about changing the language on their devices from English to another language. Older adults also sought information on how to download open and close apps, connect to $\mathrm{Wi}-\mathrm{Fi}$, surf the web, complete software updates, download anti-virus, and manage storage and data. For instance, an undergraduate female student mentor documented after a session with a woman in her mid-sixties:

"She was confused about the difference between the terms download/upload, and so we began by clarifying the difference."

\section{Basic functions}

Many older adults needed help learning basic functions of technology, which included an orientation to devices and programs, making tactile functions easier, creating accounts, setting and restoring passwords, and understanding basic cyber security. These inquiries were related to many different types of technological devices, including laptops, tablets, and mobile devices.

Examples where older inquired about basic technology functions included: turning devices on and off, charging devices, and learning the function of different buttons, icons and programs. For many participants learning the technology basics was necessary to use technology for more advanced purposes. A female undergraduate mentor reflected how she assisted a participant in his mid-seventies learn the basics of his flip phone:

"We walked through the basics of the functionality of the phone, and he seemed to grasp the concepts quickly once they were explained to him. He stated that no one had taken the time to help him with the issues he was having, and it made
Sessions also covered system and application software, as well as using input devices (e.g., mouse, keyboard, touch screen). For example, sessions helped older adults understand the purpose of different icons, buttons, and keyboard functions (e.g., enter and backspace) as well as getting acquainted with using a mouse or touchscreen device. Mentors taught tasks such as minimizing and maximizing windows, copying and pasting, and downloading and uploading documents.

Mentors accommodated older adults' unique preferences as to whether they favored using a keyboard, mouse, or touch screen. Some older adults found typing on iPads and smartphones challenging due to the small characters. Two mentors taught a male participant:

"To avoid typos, we told [him] to hover his finger as he typed something on his phone or iPad to avoid hitting other keys at the same time."

Another mentor showed an 80-year-old female to hold the phone sideways when texting to make 
the keyboard bigger. Voice commands and messaging were suggested for older adults with compromised vision or for those who wanted to find information quickly. Voice command was very useful for a participant who was legally blind:

"[This] made it easier for her because she cannot see the screen all that well at times. We taught her that just by saying 'OK Google' when on the homepage, she can do a voice command to search the internet."

A female mentor helped a 70-year-old male set up his Android phone and noted: "I showed [him] how to enlarge font, and we also discovered an 'Easy Mode,' which allowed him to access apps easier." Understanding and adopting to participant preferences and age-related cognitive and physical decline can help older adults successfully adopt to technology.

Many older adults needed help creating accounts and resetting and retrieving passwords. One female undergraduate mentor helped set up iMessage and reset a participant's Apple ID password on his devices. Mentors also reviewed pin numbers and confirmation codes and helped them set-up and understand how password retrieval functions work. Many older adults were also concerned about cyber security, and previous work has found that teaching older adults how to safely browse the internet can protect privacy, prevent identity theft, and reduce barriers to technology adoption (Betts et al., 2017). One female undergraduate mentor eased a participant's concerns:

"IShe] is very afraid about cyber security and what can and cannot be trusted. I explained to her the safety components of WiFi and made her feel a little safer about using her phone. Before she only used it for calling and texting because she was so worried about cybersecurity."

When needed, mentors referred participants to more advanced resources for cyber security, but many mentors worked to alleviate concerns and help with basic cyber security issues. One female undergraduate mentor described to an older adult when to have a device remember personal information. This mentor noted:

"I expressed how she should never let a public computer remember any of that information and only to have her personal devices remember them."

Overall, findings suggest older adults need support to learn technology basics, in order to gain the ability to safely use technology to feel connected and nourish interests.

\section{Staying connected}

Many older adults were interested in learning multiple forms of technology to stay connected. Topics included making phone calls, checking missed calls/voicemails, texting, emailing, video confer- encing (e.g., Facetime/Skype), sending video/voice and/or picture messaging, and group emailing and messaging. Older adults were interested in using social media to communicate and stay connected.

In order to use these communication mediums, older adults frequently asked various questions to better understand how these mediums worked. For instance, one undergraduate female mentor assisted a female participant and her sister by explaining the differences between the mail and messaging application. The female mentor helped another 80-year-old female send a text message and use a contact book to talk with others. The mentor logged how excited the participant was to finally send a text message.

Sessions frequently revolved around using email, such as how to type in contacts and how to compose/send emails. One female undergraduate mentor helped a small group of older adults create an email address and send and read emails. This mentor noted teaching the group:

"I showed the button on the iPad that has the option to 'reply' so the members did not have to keep on typing in the email address of the person they were trying to contact... Beyond technology we discussed friendships and staying in contact with them and how it has become increasingly difficult in older age"

Older adults interested in social media inquired about Facebook, Twitter, and Instagram. Mentors went over the basic features of Facebook, including creating a profile, accessing Facebook from smart phones, adding friends, using Facebook messenger, uploading pictures, writing statuses and posts, and sharing links. Students informed older adults how to recognize new notifications or messages to stay current on social media apps. For example, one female mentor taught a participant how to unfollow Facebook friends instead of de-friending. Another 60-year-old participant wanted to understand the difference between the Facebook homepage and her profile. A 55-yearold female inquired about hashtags and ended up creating a twitter account during her session. A female mentor reflected after the session:

"She wanted to know if there is a certain etiquette for using emojis. I told her that there is not however, they can be used to convey emotions to [one] another."

The main reason for learning how to use communication mediums was to stay connected with family and friends. For instance, a female undergraduate mentor, worked with a female participant on messaging and email and noted:

"We also added her family into her contacts on the iPad and sent them all emails." 
Another female Pharmacy student taught a 60-year-old how to Skype because he wanted to stay in contact with his wife the whole time, he was abroad. A 70-year-old participant learned how to Skype to connect with childhood friends. Mentors helped participants narrow down searches to track down relatives, using a google search to identify if someone was on Facebook. A 50-yearold female participant was looking to connect with distant relatives to collect information on her family history for a book she was writing. During this session the mentor helped the participant search for people on Facebook, and the participant also told her mentor about her public page that brought women together for bible study.

A few older adults wanted to use technology for more traditional communication methods. One inquired about downloading a letter template, some wanted to create cards, and another wanted to create address labels. While most participants saw technology as a way to stay connected, a 70-year-old participant:

"was a little frustrated because she said her family is 'forcing' her to use technology and she was not a big fan of it."

\section{Organization}

Student mentors worked with participants to get organized across three main areas: (1) Organizing programs, files, and contacts on a device; (2) Keeping track of passwords; (3) Using their device as an organization tool to keep track of appointments and reminders. Participants needed help organizing files, apps, emails, and websites, as well as how to manage storage, and download, open, close and delete applications, files, programs, emails, and messages. Other older adults also inquired about cloud computing software, such as Google Drive, Dropbox, iCloud, and OneDrive. The following are specific ways mentors helped older adults get organized, which can help minimize confusing and enhance technology adoption: "She had not organized her documents before, so I showed her how to create a folder, and how to rename files, etc. In her email, I showed her how to star emails, and move some to different inboxes." - Female undergraduate mentor and 88-year-old

"He was working on a novel and saved it in many different documents and wasn't able to find it after he saved it. I helped him save it to a single file and helped him find the document in his computer." - Female Pharmacy student and 70-yearold participant

Other participants learned to use Google Drive to backup files that were on their computer or how to share documents through google drive. Several participants also wanted to sync emails on devices.
Mentors also advised participants of options for how to keep track of passwords, such as writing them down in a safe place or through the use of secure apps. A female undergraduate mentor helped a male in his mid-seventies create an online account for password management. She documented:

"We created him an online account for one password. Essentially, this app allows him to have one universal password in which is very difficult to be hacked."

Some participants wanted to learn how to plan and organize their days by utilizing alarms, reminders, calendars, and organizing contacts. One female mentor described educating a female around age 70 on how to set alarms on her phone while on vacation. The mentor documented:

"I taught her how to set an alarm and how to customize it to the days of the week she wants it to go off."

Two undergraduate mentors working with a male participant:

"showed him how to set an alarm in his reminders for an event, such as a doctor's appointment."

One female undergraduate mentor worked with a participant in her seventies on her iPad and documented:

"Using the calendar was her favorite thing we worked on, and I showed her how to create events."

Another female mentor, described how she helped a 68-year-old female fix the calendar on her iPhone:

"...She had previously added appointments, but they were not showing up on the days they were supposed to. I showed her how to turn the proper calendar option on..."

Participants also wanted to learn how add, manage, and organize their contacts on their device or within their emails.

\section{Leisure activities}

Leisure activities of interest were related to music, movies and videos, nourishing hobbies, e-Books, planning trips, utilizing maps and GPS apps (e.g., Waze, Google Earth), car service apps (e.g., Lyft, Uber), games (e.g., Pokémon GO, Casino Cash Cats Kitty Slots, word searches, solitaire), and online shopping. Participants also inquired about various music streaming websites and programs, including Spotify, Pandora, iTunes, Google Play, and YouTube. Two undergraduate mentors explained the difference between Spotify and iTunes to a male participant, and they helped him purchase some music for his iPad. For this participant he reminisced about his youth with his wife: "He mentioned how they used to go dancing and said he would bring in a picture of them dancing 
together. He was so happy when we put the music on his iPad. He said he wished his wife were there to hear it."

During a group session, a student further reflected on how music was part of the session:

"Beyond technology we discussed a mutual love of music and a desire to learn more about access to it and information about various artists and songs."

Participants were interested in creating YouTube accounts to access music and watch videos. Some older adults even wanted to learn how to make and upload their own videos.

Many older adults in the program wanted to foster hobbies and interests (e.g., poetry, cooking, and blogs). One 55-year-old hoped to one day publish her own blog, as "she wanted to reach out to other women who may be struggling and provide them with some inspiration."

Many participants also expressed interest in Pinterest. A small group session with five older adults covered Pinterest. Following the session, the undergraduate female mentor reflected:

"They all seemed to have an interest in knitting and other activities that inspired creativity...Beyond technology we got to learn what each person was interested in and what they found to be useful in their day to day lives."

Pinterest uses images to relay information and may be an easy application for older adults to sustain hobbies, organize interests, and discover new ideas.

Finally, participants often inquired about utilizing maps, GPS apps, transportation apps, and making travel arrangements online. Mentors went over Google maps, Waze, and other GPS apps, including features such as the details option to see route info and the easiest and quickest way to get to a destination. An 80-year-old male participant informed a male Pharmacy mentor about Waze as an easy to use GPS app. A few participants were interested in apps such as Uber and Lyft. Mentors helped participants look up hotel rates, redeem airline miles, and book an Airbnb. For example, a female Pharmacy student helped a 70-year-old female review options for booking through Airbnb, and the participant appreciated being able to review and understand all the details of the website with the mentor.

Some older adults also inquired about purchasing apps and online shopping. A helpful hint for downloading games was determining if there was a cost for the app. For one participant, mentors "showed her that she could preview what the games look like and read other people's reviews before downloading the game."

One undergraduate mentor helped a female in her seventies who had difficulties finding petite clothes in stores shop for clothes. Empowering older adults to shop online is especially helpful for those with limited access to transportation, with limited in-store buying options, or with limited mobility.

\section{Photo management (Multimedia management)}

Many older adults wanted to learn how to take, view, upload, edit, organize, print, and share photos/videos via text, email, Facebook, and Instagram. Mentors described showing older adults how to use the flash and focus, and take a selfie, panoramic picture, or video. Some participants were not sure how to access, enlarge, and/or delete photos, transfer pictures from a phone to camera, or organize pictures and videos into folders. Other participants wanted help uploading photos to websites such as Facebook and Craigslist, tagging photos on Facebook through facial recognition, creating and uploading YouTube videos, and editing photos on programs (Pixlr and Shutterfly). Some participants needed help downloading photos from their email. A female undergraduate mentor working with a woman in her mid-seventies, documented:

"She truly loves the images that her son sends to her via email and would like to save the images to her albums."

During sessions older adults shared photos with their mentors, which usually included places they traveled or pictures of their family. The following are examples of the types of photos older adults took and how their multimedia use increased social connectedness:

"I learned that she is going on vacation and that she is really excited about it and plans on taking many pictures, so she can share her traveling experiences with others." - Female undergraduate mentor and a participant in her 70s learning to take and send photos

"He takes pictures of the places he visits (Antarctica, Galapagos) and puts them into PowerPoint presentations." - A male Pharmacy student and an 83-year-old participant

"We both really enjoy photography and we spent some time swapping photos, and she was telling me some interesting places around [the community] to shoot." - Female undergraduate mentor and a female participant, mid-seventies

\section{Productivity}

Some older adults were interested in learning technology to stay productive, including for professional development and to promote entrepreneurial endeavors. Technology allowed older adults to complete tasks that allow them 
to contribute to society. Mentors instructed older adults on Microsoft office programs (Word, Excel, PowerPoint), as well as promoting their creative work. The following are instances where mentors helped older adults with tasks related to professional, volunteer, and educational endeavors:

"[She] is an author and recently had a book published and wanted assistance using her personal Facebook page and public Facebook page used to promote her book." -Female Pharmacy student and a 65-year-old female

"Both needed help designing a website for a community organization they were running. I taught them how to use google drive to make polls and forms. I also showed them out to use features on the actual website design."- Male Pharmacy student \& 2 participants in their sixties

"I helped [him] add volunteer work to his resume and make it appealing to the eye. I was able to help him condense it to 1 page instead of having a few lines on a separate page. He didn't have a specific job in mind, so it was difficult to show him how to upload it online but I showed him a general way of uploading so he had an idea in the future...[He] was very inspiring. He was in his 70 s and retired but wanted to find a job to keep himself busy." - Male pharmacy student and a 72-year-old male

"We went over Word, APA formatting and Blackboard considering she is planning on going back to school." - 2 mentors and a 68-year-old female

\section{Money management}

To a lesser extent, older adults were interested in using technology to manage their finances. For older adults interested in technology for money management, they inquired about creating budget sheets on excel, mobile banking apps, selling goods on eBay/Craigslist, or investing in the stock market. Three participants were interested in coupon apps for restaurants or groceries.

\section{Health}

A few older adults inquired about using technology for health-related purposes. One participant asked about the health app on a smartphone. This participant, as well as one other participant were interested in searching for health information online, specifically Medicare Part D plans and "the benefits of coconut oil" and "yoga," respectively. One participant was interested in tracking her Tennis sessions, and another participant needed help uploading documents to a website for medical purposes. The limited interest in technology for health-related purposes may be due to older adults' digital competence level. Programs interested in utilizing digital health in aging populations should assess older adults' technology use and preferences and provide older adults with proper orientation to technology before implementing digital health services. Helping older adults utilize technology for health-related purposes is certainly an opportunity for program or intervention work and one in which many healthcare professionals should be interested in exploring.

\section{Discussion}

Findings from this study reveal that most older adults are interested in learning technology basics as well as utilizing technology to stay connected and get organized. Many novice technology users participating in our program wanted to learn the different features of their devices as well as software and applications and how they can benefit from using these programs. Such findings support using the adult learning theory when teaching older adults how to use technology. This program is unique because it offers mostly one-on-one mentoring for older adults to learn about areas of technology of interest. To our knowledge, there is limited research in such an individualized approach to teach older adults about technology. Specifically, our program allows for one-on-one reverse mentoring where older adults decide which areas of technology, they are most interested in learning.

Qualitative analyses from our study revealed many participants needed help understanding how to use their devices (i.e. basic functions and getting organized to effectively use their devices and optimize added benefits of technology use). Helping older adults understand how their devices are connected, keep track of passwords, and systematically save documents and files will decrease apprehension and negative feelings around technology. In addition to keeping track of logins and passwords, older adults in this study expressed concerns related to cyber-security and protecting privacy. This has been a concern in past research assessing older adults' perceptions of digital technology (Betts et al., 2017). Offering programs such as ours can help ease older adults concerns and help them safely use technology without compromising their personal information.

Most older adults in this study inquired about forms of communication including texting, emailing, messaging, videoconferencing, and social media. Older adults wanted to use these mediums of communication to stay connected with family and friends. These findings are consistent with previous research (Erickson \& Johnson, 2011; Hilt \& Lipschultz, 2004; Vroman et al., 2015). Utilization of communication mediums can help promote social connectivity, reduce feelings of isolation, and build and maintain relationships (Vroman et al., 2015), which becomes increasingly difficult with age. Moving beyond communication and being able to use technology for leisure activities can further promote social engagement and further improve the health and well-being of older adults. For instance, some of 
our participants were using technology to shop online, book trips, listen to music, watch videos, play games, and participate in community engagement. While our study did not measure changes in psychological well-being or attitudes toward technology, Chiu et al. (2016) found that older adults' perceptions of internet using opportunities via touch screen devices were most positive in the areas related to expanding social networking, gathering useful information, leisure, life enrichment, improved physical health, and happiness. Chiu et al. (2016) used self-directed learning strategies in a small group setting to teach older adults how to use applications for entertainment, health, social media, and transportation; this intervention was found to significantly reduce depressive symptoms among older adults. Our study also uses self-directed learning strategies but provides the opportunity for one-on-one or small group learning, mirroring recommendations from Betts and colleagues (2017). Helping older adults increase their ability to use technology for leisure can be especially beneficial for homebound older adults with disability or a chronic disease to help them stay engaged and reduce feelings of isolation.

Mastering these topics may allow for advancement in technology use in the areas of leisure, civic and productive engagement, finance, selfgrowth, and health. For example, learning how to text message well might lead to using Skype to call someone, which may eventually lead to using technology for other reasons, such as tracking diet or steps. This program incorporates core concepts of Knowles' theory of andragogy by allowing older adults to pick aspects of technology they are interested in learning about, which may help older adults understand the personal benefits they can gain through technology adoption. Past research shows older adults' perceived usefulness and potential benefit of a device or program are key technology adoption factors (Lee \& Coughlin, 2014). Technology use and increased digital literacy can also promote productive aging. This was exhibited by some of our participants who were interested in using technology for writing and promoting books and blogs for publication, applying for jobs, and education advancement. Increasing digital literacy can help older adults attain the necessary skills to be a part of today's workforce (Czaja, 2017).

Few of our participants were interested in using technology for financial and health-related purposes. This lack of interest with such programs is concerning, as these services are rapidly becoming digital. For instance, in 2017 alone there was $\$ 5.88$ billion in venture funding for digital health services (Rock Health, 2017), and of 100 U.S. health institutions surveyed, $76 \%$ offer or are planning to provide telemedicine services (Foley \& Lardner LLP, 2017). Online banking and billing, use of smart watches, healthcare portals, video appointments with healthcare providers, as well as applications to track health, diet, and exercise can easily be learned by older adults with proper training and support. A 2018 report found that $33 \%$ of healthcare consumers use wearables to track health and fitness, and 48\% use mobile/ tablet health apps (Accenture LLC, 2018). Use of digital technology to manage health, such as downloading lab results or emailing or videoconferencing with a doctor, has become increasingly popular among millennials, but older adults seem to lag in adoption to digital health (Accenture, LLC, 2018). A model similar to Cyber-Seniors may be an opportunity for entities exploring how to increase technology use among older adults for health-related purposes.

\section{Study limitations}

While this study is novel, it is not without limitations. Using observation logs from students is imperfect because students cannot be forced to keep thorough logs. We worked diligently to check the logs and encourage students to log after each session, but the reality is that some forgot, chose not to, or did not fully write about their experience. Further, the majority of the older adult participants were female, and findings may not be generalizable to male older adults. However, this is an interesting finding since past research shows that female older adults lag behind male older adults in technology adoption, specifically digital devices and internet use (Kim, Lee, Christensen, \& Merighi, 2017; Pew Research Center, 2014). Findings from Kim and colleagues (2017) also found that women who used information and communication technology had an increased likelihood to take part in formal social participation opportunities, including volunteering, religious participation, and attending classes, clubs or organized activities. Such findings may help explain why a higher proportion of female participants were involved in our program. Additionally, this study included participants who had interest in using technology, and this may not be generalizable to those older adults in the first level of the digital divide, who have limited access to the technology. Finally, future research could analyze long-term outcomes for program participants in order to understand how technology adoption changes the lives of participants.

\section{Conclusion}

The URI's Engaging Generations: Cyber Seniors Program not only helps bridge the digital divide, but also connects two generations. This program also helps promote civic engagement and servicelearning in college students and prepares students for roles as future health and human service pro- 
fessionals. By providing one-on-one education, student mentors gain exposure in how to provide person-centered care, and understand the novel needs, predispositions, and preferences associated with aging (Braun, 2013; Vroman et al., 2015). Findings from this study reinforce that older adults are interested in learning the technology basics, which may lead to utilization of technology for social, civic, and productive engagement in addition to managing health. Follow up data on how older adults progress in their digital literacy and competence is warranted as well as strategies used to teach older adults about technology in one-on-one settings.

\section{Acknowledgements}

This project was supported in part by the Rhode Island Geriatric Education Center (Grant No. UIQHP28737-02-00) for the Geriatrics Workforce Enhancement Program in the Health Resources and Service Administration.

\section{References}

Accenture, LLC (2018). 2018 Consumer survey on digital health results. Retrieved from https://www.accenture.com/t20180306T103559Z__w__/us-en/_acnmedia/PDF-71/accenture-health-2018-consumersurvey-digital-health.pdf

Bazeley, P., \& Jackson, K. (2013). Qualitative data analysis with NVivo. (2nd edn). Thousand Oaks, CA:Sage.

Betts, L. R., Hill, R., \& Gardner, S. E. (2017). "There's not enough knowledge out there": Examining older adults' perceptions of digital technology use and digital inclusion Classes. Journal of Applied Gerontology, 733464817737621. https://doi. org/10.1177/0733464817737621

Blažun, H., Saranto, K., \& Rissanen, S. (2012). Impact of computer training courses on reduction of loneliness of older people in Finland and Slovenia. Computers in Human Behaviors, 28(4), 1202-1212. https://doi.org/10.1016/j.chb.2012.02.004

Braun, M. T. (2013). Obstacles to social networking website use among older adults. Computers in Human Behavior, 29(3), 673-680. http://dx.doi. org/10.1016/j.chb.2012.12.004

Chiu, C. J., Hu, Y. H., Lin, D. C., Chang, F. Y., Chang, C. S., \& Lai, C. F. (2016). The attitudes, impact and learning needs of older adults using apps on touchscreen mobile devices: Results from a pilot study. Computers in Human Behavior, 63, 189-197. https://doi/org/10.1016/j.chb.2016.05.020

Choi, N.G., \& Denitto, D.M. (2013). Internet using among older adults: association with health needs, psychological capital and social capital. Journal of Medical Internet Research, 15(5):e97. https://doi. org/10.2196/jmir.2333

Czaja, S.J., Charnesss, N., Fisk, A.D., Hertzog, C., Nair, S.N., Rogers, W.A., \& Sharit, J. (2006).

Factors predicting the use of technology: findings from the center for research and education on aging and technology enhancement (CREATE). Psychology and Aging, 21, 333-352. https://doi. org/10.1037/0882-7974.21.2.333

Czaja, S. (2017). The potential role of technology in supporting older adults. Public Policy \& Aging Report, 27(3), 44-48. https://doi.org/10.1093/ppar/prx006

Delello, J. A., \& McWhorter, R. R. (2017). Reducing the digital divide: Connecting older adults to iPad technology. Journal of Applied Gerontology, 36(1),

\section{3-28. https://doi.org/10.1177/0733464815589985'}

Eastin, M. S., \& LaRose, R. (2000). Internet self-efficacy and the psychology of the digital divide. Journal of Computer-Mediated Communication, 6(1).

Erickson, J., \& Johnson, G. M. (2011). Internet use and psychological wellness during late adulthood. Canadian Journal on Aging, 30(2), 197-209. https://doi. org/10.1017/S0714980811000109

Fink, A. \& Beck, J. C. (2015). Developing and evaluating a website to guide older adults in their health information searches: A mixed-methods approach. Journal of Applied Gerontology, 34(5), 633-651. https://doi.org/10.1177/073346481348696

Foley \& Lardner, LLP (2017). Telemedicine and digital health survey. Retrieved on June 1, 2018 from https://www.foley.com/files/uploads/2017-Telemedicine-Survey-Report- 11-8-17.pdf

Heart, T., \& Kalderon, E. (2013). Older adults: Are they ready to adopt health-related ICT?. International Journal of Medical informatics, 82(11), e209-231. https://doi.org/10.1016/j.ijmedinf.2011.03.002

Heinz, M., Martin, P., Margrett, J. A., Yearns, M., Franke, W., Yang, H. I., Chang, C. K. (2013). Perceptions of technology among older adults. Journal of Gerontological Nursing, 39(1), 42-51. https://doi. org/10.3928/00989134-20121204-04

Hilt, M.L., \& Lipschultz, J.H. (2004). Elderly Americans and the internet: E-mail, TV news, information and entertainment websites. Educational Gerontology, 30(1), 57-72. https://doi. org/10.1080/03601270490249166

Josselson, R. (2011). Narrative research: Constructing, deconstructing, and reconstructing story.

In F.J. Wertz, K. Charmaz, L.M. McMullen, R. Josselson, R. Anderson, and E. McSpadden (Eds.), Five ways of doing qualitative analysis (pp. 224-242). New York, NY: The Guilford Press.

Karavidas, M., Lim, N., \& Katsikas, S. (2005). The effects of computers on older adult users. Computers in Human Behavior, 21(5), 697-711. https://doi/ org/10.1016/j.chb.2004.03.012

Kim, J., Lee, H. Y., Christensen, M. C., \& Merighi, J. R. (2017). Technology access and use, and their associations with social engagement among older adults: Do women and men differ? J Gerontol B Psychol Sci Soc Sci, 72(5), 836-845. https://doi. org/10.1093/geronb/gbw123

Knowles, M. and Associates (1984). Andragogy in action: Applying modern principles of adult learning. San Francisco: Jossey-Bass.

Lee, C. \& Coughlin, J.F. (2014). Perspective: Older adults' adoption of technology: An integrated approach to identifying determinants and barriers. The Journal of Product Innovation Management, 
32: 747-759. https://doi.org/10.1111/jpim.12176

Leedahl, S.N., Brasher, M.S., Estus, E., Breck, B.M., Dennis, C.B., \& Clark, S.C. (2019). Implementing an interdisciplinary intergenerational program using the Cyber Seniors ${ }^{\circledR}$ reverse mentoring model within higher education. Gerontology \& geriatrics education, 40(1), 71-89

Peek, S. T., Luijkx, K. G., Rijnaard, M. D., Nieboer, M. E., van der Voort, C. S., Aarts, S., Wouters, E. J. (2016). Older Adults' reasons for using technology while aging in place. Gerontology, 62(2), 226-237. https://doi.org/10.1159/000430949

Pew Research Center. (2017). Tech adoption climbs among older adults. Retrieved from http://assets.pewresearch.org/wpcontent/uploads/ sites/14/2017/05/16170850/PI_2017.05.17_OlderAmericans-Tech_FINAL.pdf

Pew Research Center. (2014). Older adults and technology use. Retrieved from http://www.pewinternet. org/2014/04/03/older-adults-and-technology-use/

Reeder, B., Meyer, E., Lazar, A., Chaudhuri, S., Thompson, H. J., \& Demiris, G. (2013).

Framing the evidence for health smart homes and home-based consumer health technologies as a public health intervention for independent aging: a systematic review. International Journal of Medical Informatics, 82(7), 565-579. https://doi.org/0.1016/j. ijmedinf.2013.03.007

Rock Health. (2017). Digital health funding: 2017 year in review. Retrieved on June 1, 2018 from https:// rockhealth.com/reports/2017-year-end-funding-report-the-end-of-the-beginning-of-digital-health/

Saladaña, J. (2016). The coding manual for qualitative researchers. (3nd edn). Thousand Oaks, CA: Sage.

Speitzer, G.M. (2006). Leading to grow and growing to lead: Leadership development lessons from positive organizational studies. Organizational Dynamics, 35, 305-315. https://doi.org/10.1016/j. orgdyn.2006.08.005

Teaching Excellence in Adult Literacy (TEAL) Center Staff. (2011). TEAL center fact sheet no.11: Adult learning theories. Retrieved from https://lincs. ed.gov/sites/default/files/11_\%20TEAL_Adult_ Learning_Theory.pdf

Tsai, H.S., Shillair, R., Cotten, S.R., Winstead, V., \& Yost, E. (2015). Getting grandma online: Are tablets the answer for increasing digital inclusion for older adults in the U.S.? Educational Gerontology, 41(10), 695-709. https://doi/org/10.1080/03601277.2015.1 048165

Tun, P., \& Lachman, M. (2010). The association between computer use and cognition across adulthood: Use it so you won't lose it? Psychology and Aging, 25(3), 560-568. https://doi.org/10.1037/a0019543

Underwood, H. L., \& Dorfman, L. T. (2008). A view from the other side: Elders' reactions to intergenerational service-learning. Journal of Intergenerational Relationships, 4(2), 43-60. https://doi. org/10.1300/J194v04n02_04

van Deursen, A.J. A. M. \& Helsper, E.J. (2015) The thirdlevel digital divide: who benefits most from being online? In: Robinson, Laura and Cotten, Shelia R. and Schulz, Jeremy and Hale, Timothy M. and Williams, Apryl, (eds.) Communication and Information Technologies Annual. Studies in Media and Communications,10. Emerald, pp. 29-52. ISBN 9781785603815

van Dijk, J. A. G. M. (2006). Digital divide research, achievements and shortcomings. Poetics, 34(4-5), 221235. https://doi.org/10.1016/j.poetic.2006.05.004

Vroman, K. G., Arthanat, S., \& Lysack, C. (2015). "Who over 65 is online?" Older adults' dispositions toward information communication technology. Computers in Human Behavior, 43, 156-166. http:// dx.doi.org/10.1016/j.chb.2014.10.018 